\title{
Making Students Think More Critically
}

\author{
Nele Van den Cruyce
}

VRIJE UNIVERSITEIT BRUSSEL

\author{
Barry Brummet \\ Sage, Los Angeles, 2011 \\ ISBN 9781412975681 \\ RRP US\$49.95 (pb)
}

Rhetoric in Popular Culture (third edition)

As a (post)graduate student I have been surprised by the amount of literature available on different methodologies aimed at researching media content. With the rise of the new media and the ever-changing media culture, the classical methodologies face adaptation. Because of the origin of rhetoric dating back to a spoken art form in ancient Greece, rhetoric can be seen as a classic among classics. With several historical evolutions (explosion of population numbers, rise in technology, pluralism, increase in knowledge) the definition of rhetoric has broadened to encompass a much larger setting including verbal and nonverbal texts, diffuse and discrete texts, and so on. Its followers seem to be determined to keep on adapting rhetorical theory to a changing world, including not only high culture but also popular culture, the latter being the focus of Barry Brummet's work. However, while there appears to be a lot written on the theoretical notions of contemporary rhetorical thought and researchers use rhetoric analysis in their research, finding 
practical hands-on guidelines is not always easy. Therefore, I was pleased to read and review the third edition of Rhetoric in Popular Culture. After all, the book does explicitly promise to cover a combination of theory and practical method application.

Based on this promise, the textbook is made up of two larger parts, the first covering the theory and the second focusing on its application. Both parts consist of five chapters and have a structured layout. Exercises and the use of visual material and examples, although mostly Anglo-American, are practical for the reader, offering a deeper and more personal understanding of what is being discussed in general. Brummet's aim is to combine the traditional study of rhetoric with new critical studies as this is, in his view, the most exciting form of rhetorical criticism today.

The textbook starts with an open question to the student reader: think about how every day actions, objects and experiences affect people. This question is made more tangible through some real life examples; for example, societal beliefs concerning gender and power relationships and its physical sediment in popular culture (clothing, work-life balance, stereotypes, expectations, and so on). A basic idea which indicates the essence of rhetorical thought is that social reality is the result of struggles of meaning over what kind of society we (will) live in and what sort of people we will be. The result of the struggle is group related, contingent but not arbitrary. The role of power, the ability to control events and meanings in a certain group, is therefore essential in rhetorical criticism. It immediately becomes clear that rhetoric can be used in considering different types of questions (compare with feminism, Marxism, media representation and so on). After this general acquaintance with the notion of rhetoric, the basic components of rhetorical thought and their specifics, such as signs and artefacts, are explained.

The second chapter of the first section illustrates the long history of the rhetoric tradition. Starting from ancient Greek democracy and public speaking, the debate between the Sophists and Plato is discussed to show that the power question was already present at the origin of rhetorical theory. After Aristotle, not only the act of public speaking was analysed but any given situation intended to persuade people was considered as part of rhetorical knowledge. Because of different evolutions, mentioned above, the definition of rhetoric has since broadened to incorporate modern text forms. Rhetoric is no longer restricted to discrete texts but 
also looks at diffuse texts. Rhetoric is concerned with verbal as well as nonverbal texts. All texts are liable for rhetorical analysis, including popular ones. The question remains as to what rhetorical criticism practically entails and how to go about it.

Chapter Three of the theoretical section is designed to make clear what rhetorical criticism is. First, two basic premises are stated. Texts influence through meaning, and texts are sites of struggle over meaning. Then it is explained what it means to be critical or to perform critical studies based on three characteristics of critical studies. One first common element is that the studies are critical in attitude and method. They do not take things at face value and adopt an attitude of suspicion. The questioning is therefore concerned with the complexity of texts, with what they mean to different people. According to Brummet, the aim of the critical method is also to make an evaluation, a judgment about what is studied in terms of good or bad, desirable or not. While I do agree that scholars have a responsibility to society in showing the existence of different meanings and the construction process of those meanings, I am not entirely sure or convinced about the moral judgment aspect proposed by the author. It is after all not always clear cut. Neither do I agree with the author's claim that critical research inevitably implies qualitative research. Contemporary frame analysis-conceptualising the influence of frames used in communication (compare framing illegal immigrants, framing television news on public or private broadcasting stations) - could be regarded as a form of critical study often based on rhetorical principles which is not always restricted to qualitative research. With the development of mixed methods, I do believe that the strict boundary between qualitative and quantitative methods has to be reconsidered in general. A second common element of critical studies is that they are concerned with the aspect of power in certain groups. A last common characteristic is critical interventionism, wanting to be involved in the world, changing it for the better. While this sounds like a derivative of the moral judgment implied by the critical method, Brummet explains this last common aspect in terms of power; that is, showing people different realities is liberating and this intervention is the task of critical studies. This explanation is more acceptable, to me, than the demand of a moral judgment. After explaining what it means to be critical, Brummet suggests that the choice of a text to analyse always implies some choices when wanting to work critically. These choices are set among continua that 
include discrete versus diffuse texts, broad versus narrow sources of meanings, original or new context, reactive or proactive reading, looking at direct or implied strategies versus structures. It is therefore important to always look at the broader context of the text and to remain critical.

The two last chapters of Part One are dedicated to specific forms of rhetorical criticism. Brummett suggests that all forms are to be used in a sort of bricolaged way. The concepts and categories that a theory or method offers should be used but not as strict unbendable rules. The real payoff of criticism is insight into what texts mean, and critical methods should therefore serve that end instead of becoming rigorous machinery. This flexibility is welcome since several types of rhetorical criticism can offer different kinds of insight into similar questions. However, it may also prove to contribute to the confusion of finding and executing a specific method. Maybe this is why Brummet does not describe specific research steps for rhetorical criticism, as it seems to be expected the researcher will create a personal combination method. A variety of rhetorical forms are discussed in this textbook, ranging over culture-centered criticism, Marxist criticism, visual rhetorical criticism, psychoanalytic criticism, feminist criticism, narrative criticism and mediacentered criticism. The basic idea is that the construction processes of different areas are being unravelled by critical thinking. Each method seems to have its own vocabulary that accentuates different elements; for example, class and power relationships in Marxist criticism versus individual, mind, personality construction in psychoanalytic criticism.

Part Two is dedicated to specific application of rhetorical criticism. Five chapters offer five different examples of rhetorical analyses, ranging from race relations in Milwaukee to gansta rap. Each example offers another way of tackling a research question by means of rhetorical analysis. While the first part of the book appears structured, the second part is presented rather like a student reader with comments. There does not seem to be a logical follow up. It is obviously impossible to provide each member of a diverse reader audience with a specific example according to their needs, and Brummet does try to deliver as much detailed information as possible surrounding each example. But I do feel that, while the examples illustrate some difficulties that researchers can encounter and they do demonstrate how research can be done, a detailed deconstructed research process 
(such as a scheme, codebook or list of steps) would be more helpful to readers of a textbook.

In conclusion, it is fair to say that Brummet has written a good textbook on rhetoric criticism. Part One, especially, offers a lot of information on rhetorical criticism in a comprehensive manner. I admire the rather bold statement that the different types of rhetoric criticism can be used together in research. But the plea for bricolage does not get translated into the discussion on qualitative and quantitative methods, which I personally regret. Also, the demand for a moral judgment on behalf of the researcher is overemphasised and I would prefer to see it translated into 'liberation in offering different realities' discourse. The textbook could do with a more practical second part, in light of the first part, especially when written for a postgraduate audience. All the information is, however, present in the book and maybe the reader should personally engage in experiencing the process of bricolage in rhetorical criticism to really fully understand Brummet's examples. The textbook does indeed succeed in making the reader, the student, think more critically, which was the goal stated by Brummet at the end of his preface.

Nele Van den Cruyce is a PhD researcher at the Vrije Universiteit Brussel. Her work focuses on the area of tension between educationalisation and commercialisation in the lives of children. As a researcher she is interested in using both quantitative and qualitative methodologies, especially for content analysis. 